\title{
Comparative study between linear and non-linear modelling techniques in Rainfall Forecasting for South Australia
}

\author{
H. M. Rasel, M. A. Imteaz, I. Hossain and F. Mekanik \\ Department of Civil and Construction Engineering, Faculty of Science, Engineering and Technology, \\ Swinburne University of Technology, Melbourne, VIC 3122, Australia \\ E-mail: hrasel@swin.edu.au
}

\begin{abstract}
Australian rainfall is highly variable in nature and largely influenced by the several large scale remote climate drivers. Several past studies tried to establish the relationships between climate predictors (El Nino Southern Oscillation (ENSO), Indian Ocean Dipole (IOD) and Southern Annular Mode (SAM)) and rainfalls over Australia. However, the relationship between climate predictors and South Australian rainfall is still unclear. Most of the past studies in this region have been carried out based on the individual and concurrent relationship of climate drivers with rainfall. Moreover, the combined relationship considering lagged-time effects of multiple climate predictors has not previously been attempted in South Australia. This paper presents the application of linear Multiple Regression (MR) analysis and non-linear Artificial Neural Networks (ANN) modelling to forecast long-term seasonal rainfall in South Australia using the potential climate predictors. A rainfall station in South Australia was chosen as case study to broadly explore this present hypothesis. The use of combined lagged ENSO-IOD-SAM climate input sets for calibrating and validating the ANN and MR Models was proposed to investigate the effect of past values of these major climate modes on long-term spring rainfall. The ANN model was developed in the form of multilayer perceptron using Levenberg-Marquardt algorithm. Early stopping techniques were used to analyze the improvement in the network's generalization ability. Both the MR and ANN modelling were assessed statistically using root mean square error (RMSE), Pearson correlation (R) and Willmott index of agreement (d). Finally the superiority of rainfall predictability methods was established by comparing the both linear and non-linear techniques.
\end{abstract}

The developed MR and ANN models were tested on out-of-sample test sets; the MR models showed poor generalization ability than non-linear ANN models. This study found that predicting spring rainfall using combined lagged ENSO-DMI-SAM climate indices with ANN can achieve better correlation as compared to multiple regressions. The study discovered that lagged DMI-SAM combined climate model has more effect on spring rainfall predictability than other combinations of climate model. It was observed that ANN modelling is able to provide higher correlations using the lagged-indices to forecast spring rainfall in compared to linear methods. Using the combination of DMI-SAM dual climate indices in an ANN model increased the model correlation up to $87 \%, 76 \%$ and $37 \%$ for the three combined climate predictor's models in forecasting South Australian spring rainfall. Whereas, those rainfall predictability was 52\%, 49\% and 18\% respectively in case of linear MR modelling. The errors of the testing sets for ANN models are generally lower compared to multiple regression models. The statistical analysis suggested the potentials of non-linear artificial intelligence techniques (ANN) over linear MR models for rainfall forecasting using large scale climate modes. This method can be used for other parts of the world where a relationship exists between rainfall and large scale climate modes which could not be established by linear methods.

Keywords: MR model, ANN model, ENSO, IOD, SAM 


\section{INTRODUCTION}

Forecasting rainfall is very essential in developing a water resource management strategy to check the balance of future water supply and demand to ensure proper water supplies to the people. The ability to forecast rainfall several months or seasons has been a goal of water resource managers for many decades. A reliable rainfall forecast can be beneficial for the management of land and water resources systems (Anwar et al., 2008, Cuddy et al., 2005). Many researchers have tried to establish the relationships between large-scale climate drivers and rainfall in different parts around the world using different linear and non-linear methods (Grimm, 2011, Shukla et al., 2011). Australian rainfall is highly variable both in space and time. The variability of Australian rainfall has been linked with the several dominant large-scale potential climate predictors including the ENSO, IOD and SAM (Chowdhury \& Beecham, 2013, Cai et al., 2011, Kirono et al., 2010, Risbey et al., 2009, and Meneghini et al., 2007). A number of researches tried to find out the relationship between the climate drivers and Australian rainfalls. Some of them covers whole of Australia (Kirono et al., 2010, Risbey et al., 2009, Meneghini et al., 2007) while others are more focused on a specific region like South West Western Australia (Ummenhofer et al., 2008), South Australia (Nicholls, 2010 and Evans et al., 2009), South East Australia (SEA) and East Australia (Mekanik et al., 2013, Mekanik \& Imteaz, 2013, Mekanik \& Imteaz, 2012, Murphy \& Timbal, 2008 and Verdon et al., 2004).

Recent researches (Chowdhury \& Beecham, 2013 and Cai et al., 2011) did not find the good correlations between South Australian (SA) rainfall and climate indices. They analyzed the impact of climate indices considering concurrent \& separate role of single/isolate climate driver at a time. However, their analyses on the climate drivers were limited to ENSO and IOD only. Risbey et al. (2009) found that the SA rainfall variability was up to $15-20 \%$ considering the individual effects of ENSO and SAM climate predictors. Nevertheless, a strong relationship between simultaneous/concurrent climate driver and rainfall does not prove that there also exists lagged relationship (Schepen et al. 2012), which should be considered in rainfall forecasting. On the other hand, to the best of the authors knowledge, previous researches did not consider lagged-time effects with the multiple combinations (ENSO-IOD-SAM combined sets) of key climate indicators at a time in assessing the rainfall predictabilities.

Due to the geographical locations of Southern Victoria and South Australia, climate indices other than ENSO may also influence the rainfall. Some other potential climate indices are Indian Ocean Dipole (IOD) and the Southern Annular Mode (SAM). Mekanik and Imteaz $(2013,2012)$ found that SOI is still a strong predictor for the rainfalls of east Victoria, however moving towards west i.e. for west Victoria IOD becomes a dominating predictor. It is expected that SA's rainfalls are influenced by a combination of these climate indices (including ENSO) and that a thorough investigation of these should produce an improved predictive capacity of seasonal rainfalls. Since the relationships of climate predictors and rainfall are much more complex, only the single climate predictor might not be sufficient to predict rainfall accurately. Recently, the non-linear artificial intelligence techniques have been paid more attention in hydrological and meteorological modelling and rainfall forecasting as this technique are able to map complex non-linear input-output relationships incorporating all of the relevant climate indices into a single matrix (Mekanik et al., 2013, Mekanik \& Imteaz, 2013, Mekanik \& Imteaz, 2012), but in Australia it has been used very rarely in rainfall forecasting with the association of remote climate drivers. ANN is also known for its ability to map between the input-output variables without a prior in-depth knowledge of mechanisms. Such a non-linear relationship has not previously been attempted in SA.

The aim of this research is to investigate the combined lagged effects of the potential climate predictors for South Australian spring rainfall predictions using multiple regressions as a linear method compared to Artificial Neural Networks (ANN) as a nonlinear method. Moreover, this study would be the extension of the works conducted by Chowdhury \& Beecham, 2013, Cai et al., 2011 and Risbey et al., 2009.

\section{DATA}

\section{Rainfall Data}

Historical monthly rainfall data was obtained from the Australian Bureau of Meteorology website data base for a case study of Kersbrook Mabenjo (KM) rainfall station, South Australia. Fig.1 shows the location details of the station considered in this study. Spring (September - November) rainfall was obtained from monthly rainfall data from January 1957 to December 2013 (www.bom.gov.au/climate/data/).

\section{Climate Indices Data}

Monthly values of NINO3, NINO34 and NINO4 were used as the representation of ENSO in this study. In addition to this SST related indices, Southern Oscillation Index (SOI) which is the SLP representation of ENSO was also considered in this study. A measure of IOD is the Dipole Mode Index (DMI) which is the difference in average SST anomalies between the tropical Western Indian Ocean $\left(10^{\circ} \mathrm{S}-10^{\circ} \mathrm{N}, 50^{\circ}-70^{\circ} \mathrm{E}\right)$ and the tropical Eastern Indian ocean $\left(10^{\circ} \mathrm{S}\right.$-Equator, $\left.90^{\circ}-110^{\circ} \mathrm{E}\right)$ (Kirono et al., 2010). SAM is the major mode of atmospheric variability on the mid and high latitude of southern hemisphere. ENSO, IOD and SAM indices were obtained from Climate Explorer website 
http://climexp.knmi.nl/.

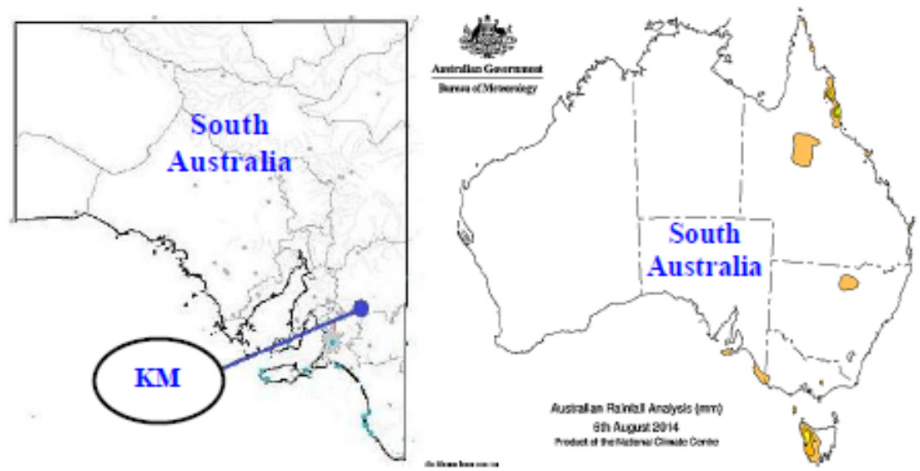

Figure 1. Map showing the study area with selected locations (Source: www.bom.gov.au).

\section{METHODOLOGY}

To achieve the goal of the study multiple regression (MR) modelling was used as a linear statistical technique and ANN as a non-linear artificial intelligence techniques. As the first step for developing a prediction model, the process of input selection is crucial. December to August values of NINO3, NINO34, NINO4, SOI, DMI and SAM climate indices were chosen to be used in ANN modeling of spring rainfall. Since these months' indices have high linear correlations with each other, it was assumed that they will provide the same information while being used in the multiple regression modeling, thus not being significant predictors. Thus, the correlation of these months' NINO3, NINO34, NINO4, SOI, DMI and SAM with Kersbrook Mabenjo (KM) rainfall was calculated and the months with highest significant correlation were chosen to be used in multiple regression modeling. This will be further discussed in the results and discussion section.

\section{Multiple Regression Modelling}

Multiple regression is a statistical technique that allows for the prediction of a variable (dependent, predictant) based on several other variables (independent, predictor). Multiple regression models can be presented by the following equation:

$$
Y=a+b_{1} X_{1}+b_{2} X_{2}+c
$$

Where, $Y=$ Dependent variable (spring rainfall), $X_{1}=$ First independent variable or predictor (ENSO representative), $\mathrm{X}_{2}=$ Second independent variable or predictor (SAM or IOD representatives), $b_{1}=$ Coefficient of first independent variable, $X_{1}, b_{2}=$ Coefficient of second independent variable, $X_{2}$, $a=$ Constant and $c=$ Error. Multicollinearity verification among the predictors is the important stage of MR modeling. It occurs when the predictors are highly correlated that result in a dramatic change in parameter estimates in response to small changes in the data or the model. The Variance Inflation Factor (VIF) is used to ascertain the multicollinearity among the predictors. Lin (2008) found that a multicollinearity problem exists among the predictors if the VIF values greater than 5-10.

\section{Artificial Neural Networks}

The parameters for ANN modelling are basically network topology, neurons characteristics, training and learning rules. Multi-Layered Perceptrons (MLP) are feed-forward nets with one or more hidden layers between the input and output neurons. Typical artificial neural network (ANN) architecture is shown in Fig. 2. The number of input and output neurons is based on the number of input and output data. Basically, the input layer only serves as receiving the input data for further processing in the network. The hidden layers are a very important part in a MLP since they provide the nonlinearity between the input and output sets. More complex problems can be solved by increasing the number of hidden layers. The output neuron is the desired output of the model. The process of developing an ANN model is to find a) suitable input data set, b) determine the number of hidden layers and neurons, and c) training and testing the network.

Mathematically, the network depicted in Fig. 2 can be expressed as follow:

$$
Y_{t}=f_{2}\left[\sum_{j=1}^{J} w_{j} f_{1}\left(\sum_{i=1}^{I} w_{i} x_{i}\right)\right]
$$

where $\boldsymbol{Y}_{\boldsymbol{t}}$ is the output of the network, $\boldsymbol{x}_{\boldsymbol{i}}$ is the input to the network, $\boldsymbol{w}_{\boldsymbol{i}}$ and $\boldsymbol{w}_{\boldsymbol{j}}$ are the weights between neurons of the input and hidden layer and between hidden layer and output respectively; $\boldsymbol{f}_{\mathbf{1}}$ and $\boldsymbol{f}_{2}$ are the activation functions for the hidden layer and output layer respectively. According to Maier and Dandy (2000) if extrapolating beyond the range of the training data is needed it is recommended to use sigmoidal-type transfer functions in the 
hidden layers and linear transfer functions in the output layer. In this study $\boldsymbol{f}_{\mathbf{1}}$ is considered tansigmoid function which is a nonlinear function and $\boldsymbol{f}_{\mathbf{2}}$ is considered the linear purelin function. Early stop technique was used to stop the network from over fitting. Number of hidden neurons was chosen based on trial and error considering 5 , $10,15,20,25,30$ and 35 hidden nodes.

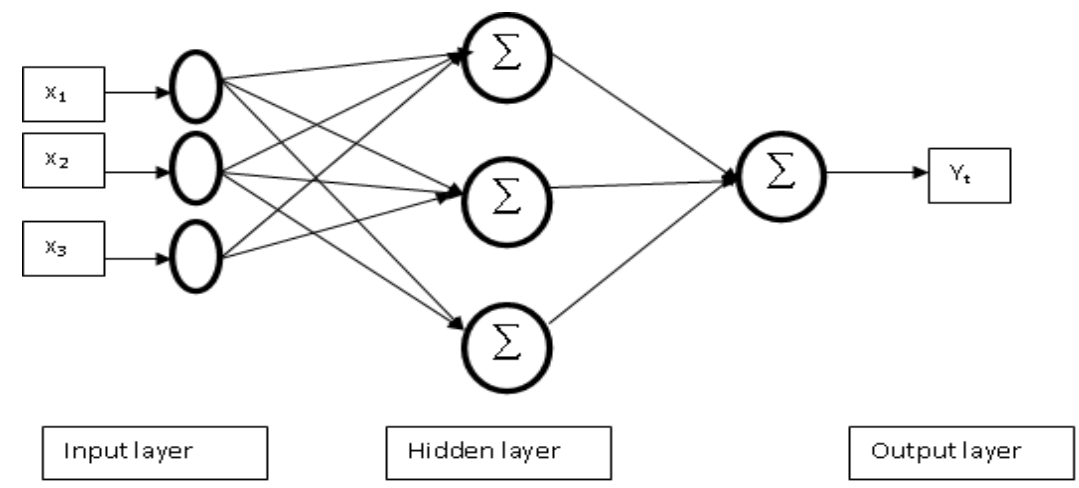

Figure 2. A typical artificial neural network (ANN) architecture

The models were evaluated using the root mean square error (RMSE), Pearson correlation (R) and index of agreement $(d)$, which are widely used for the evaluation of prediction model. The optimum value of $d$ is 1 called the better the model meaning that all the modeled values fit the observations (Willmott 1981). The SPSS statistical software was used to accomplish the single and multiple regression correlation tests. MATLAB coding was used to find the non-linear results in ANN modelling. From both cases, the correlations which are statistically significant at 1 and 5\% levels were considered in this study. The data were divided into two sets, years from 1957-2008 were used for calibration and validation of the models. Later five years from 2009-2013 were selected as the out-ofsample test set to evaluate the generalization ability of the developed forecasting models.

\section{RESULTS AND DISCUSSIONS}

The rainfall predictability was primarily evaluated by finding the single/individual correlations between south Australian spring rainfall (S-O-N) at any year ' $n$ ' with lagged monthly values of ENSO, DMI and SAM climate predictors (NINO3, NINO4, NINO3.4 and SOI were chosen as ENSO predictors) from Dec n-1-Aug $_{n}$ (' $n$ ' being the year for which spring rainfall is predicted). Table 1 shows the single linear correlation between spring rainfall and the lagged climate indices. It can be seen from Table1 that not all the considered lags have a significant linear relationship with rainfall, and the maximum correlation $42 \%$ is achieved for DMI-August. For different indices different months have significant relationship with rainfall, however July and August months are having the highest correlation with rainfall. The correlations of rainfall with single predictor within the limits of statistical significance level and multicollinearity among the predictors were chosen for further MR analysis. It was observed that the maximum three months' (June, July and August) lagged SOI, DMI and SAM climate predictors have significant correlation with spring rainfall.

Table 1. Correlation of spring rainfall with different lagged time effects of single climate indices (only the significant correlations at either 1 or $5 \%$ level are shown by an asterisk)

\begin{tabular}{|c|c|c|c|}
\hline \multirow{2}{*}{ Month } & \multicolumn{3}{|c|}{ Pearson correlation } \\
\cline { 2 - 4 } & SOI & DMI & SAM \\
\hline Dec & --- & --- & --- \\
\hline Jan & --- & --- & --- \\
\hline Feb & --- & --- & --- \\
\hline Mar & --- & --- & --- \\
\hline Apr & --- & --- & --- \\
\hline May & --- & --- & --- \\
\hline June & --- & $-28.0^{*}$ & $-34.0^{*}$ \\
\hline July & $37.0^{* *}$ & $-39.0^{* *}$ & --- \\
\hline Aug & $29.0^{*}$ & $-42.0^{* *}$ & --- \\
\hline
\end{tabular}

The combined lagged-predictor model sets were organized based on the significant single and separate lagged relationship obtained in table 1 with ENSO, IOD and SAM climate predictors. Then, ENSO-DMI-SAM based combined climate predictor model input sets were used for further multiple regressions and ANN modelling in 
order to investigate the predictability of spring rainfall with linear and non-linear models. Among the developed models the ones that follow all the limits of statistical significance level were selected, the models having lower error were chosen as the best model for rainfall prediction. The combinations of these significant lagged indices were examined in MR modelling and the Training-Validation results are as shown in Table 2 as well as the results for model testing phase is shown in table 3. It can be seen from both table 2 and 3 that combined climate indices significantly increased the correlation up to $48 \%$ in calibration and $52 \%$ in testing phase with DMI (Aug)-SAM (June) combinations. This model is shown in the following equation:

Rainfall $=63.66-28.78 \times \operatorname{DMI}($ Aug $)-2.90 \times$ SAM(June)

Table 2. Correlation of spring rainfall and multiple regression modeled rainfall at Training-Validation phase (only the significant correlations at $5 \%$ are shown by an asterisk)

\begin{tabular}{|c|c|c|c|c|c|}
\hline MR model & Correlation & MR model & Correlation & MR model & Correlation \\
\hline DMI-SOI & $\mathrm{R}$ & DMI-SAM & $\mathrm{R}$ & SOI-SAM & $\mathrm{R}$ \\
\hline June-Jul & --- & June-June & --- & Jul-June & $\mathbf{4 3 . 0}^{*}$ \\
\hline June-Aug & --- & Jul-June & --- & Aug-June & --- \\
\hline Jul-Jul & --- & Aug-June & $\mathbf{4 5 . 0 ^ { * }}$ & --- & --- \\
\hline Jul-Aug & --- & --- & --- & --- & --- \\
\hline Aug-Jul & $\mathbf{4 8 . 0}^{*}$ & --- & --- & --- & --- \\
\hline Aug-Aug & --- & --- & --- & --- & - \\
\hline
\end{tabular}

Table 3. Correlation of spring rainfall and multiple regression modeled rainfall at testing phase (only the significant correlations at $5 \%$ are shown by an asterisk)

\begin{tabular}{|c|c|c|c|c|c|}
\hline MR model & Correlation & MR model & Correlation & MR model & Correlation \\
\hline DMI-SOI & R & DMI-SAM & R & SOI-SAM & R \\
\hline June-Jul & --- & June-June & --- & Jul-June & $\mathbf{1 8 . 0}^{*}$ \\
\hline June-Aug & --- & Jul-June & --- & Aug-June & --- \\
\hline Jul-Jul & --- & Aug-June & $\mathbf{5 2 . 0 *}$ & --- & --- \\
\hline Jul-Aug & --- & --- & --- & --- & --- \\
\hline Aug-Jul & $\mathbf{4 9 . 0 *}^{*}$ & --- & --- & --- & --- \\
\hline Aug-Aug & --- & --- & --- & --- & - \\
\hline
\end{tabular}

The MR model was used to forecast rainfall for the test set of 2009-2013 and the correlation for the test set was found to be $52 \%$. Attempt has been made to use all the combined lags as predictors in MR modelling, but most of the combined-lagged indices model was not statistically significant. Therefore, those insignificant models were not reliable in rainfall forecasting. Even though some of the lags of the predictors were not linearly correlated with the rainfall, however for ANN modeling all the lagged indices were used as predictors (Dec. to Aug.). The reason behind of taking all these lags due to the concept of ANN which is capable of finding the nonlinear relationship between the predictors and rainfall. Table 4 shows the result of ANN modeling on both training-validation and testing set using the combined climate predictor's model. The best number of hidden neurons giving the least error, maximum correlation as well as maximum data agreements between observed and modelled rainfall was 6 .

Table 4. Correlation of spring rainfall with linear MR and non-linear ANN modeled rainfall

\begin{tabular}{|c|c|c|c|c|}
\hline \multirow{2}{*}{ Model } & \multicolumn{4}{|c|}{ Correlation } \\
\cline { 2 - 5 } & \multicolumn{2}{|c|}{ Training-Validation } & Testing & \multicolumn{2}{c|}{ Training-Validation } & Testing \\
\hline & \multicolumn{2}{|c|}{ Linear Regression model } & \multicolumn{2}{c|}{ Non-linear ANN model } \\
\hline DMI-SOI & $\mathbf{4 8 . 0}$ & $\mathbf{4 9 . 0}$ & $\mathbf{6 5 . 0}$ & $\mathbf{7 6 . 0}$ \\
\hline DMI-SAM & $\mathbf{4 5 . 0}$ & $\mathbf{5 2 . 0}$ & $\mathbf{4 8 . 0}$ & $\mathbf{8 7 . 0}$ \\
\hline SOI-SAM & 43.0 & 18.0 & 35.0 & 37.0 \\
\hline
\end{tabular}

The linear multiple regression modelling was further checked with non-linear ANN technique. ANN modeling is showing much higher correlation between the actual rainfall and the predicted rainfall for both DMI-SOI and DMISAM combinations. The correlation is also significantly higher than the maximum correlation found in multiple regression modeling, which was $52 \%$, however using ANN the correlations was $48 \%$ for training-validation set and $87 \%$ for the out-of-sample test set. Figure 3 shows the comparative outputs of linear multiple regression and nonlinear ANN modeling with the actual data series. It can be seen from Fig. 3 that the multiple regression models is modeling around the mean of the series and is not capable of capturing the peaks and the trough or minimum values. On the other hand ANN is smoothly fitting the series capturing almost all the peaks and minimum values, however, it can be seen that validation and test sets are not well-modeled as the training set. This can be overcome by doing a K-fold cross-validation which is going to be done in the future work. 

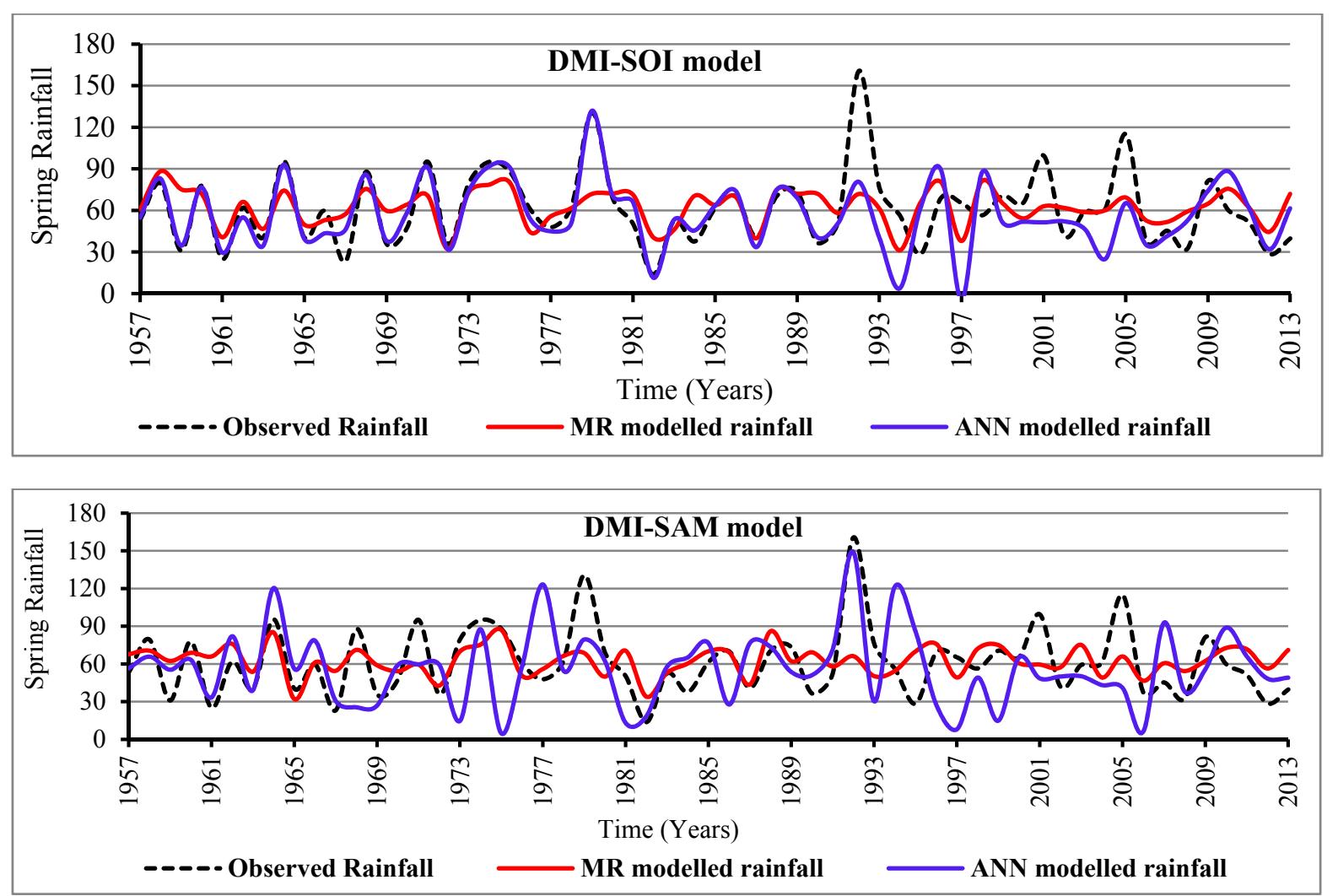

Figure 3. Comparison of different non-linear ANN model with linear Regression model's output for spring rainfall, (1957-2008=training-validation period, 2009-2013=testing period.

For the better assessment of the model's performance, an additional criterion, the Index of agreement (d) (Willmott, 1981) has been chosen for model comparison. A 'd' value close to 1 indicates a better fitted model. Table 5 shows RMSE and ' $d$ ' values for the two models. It is obvious that ANN had the least error and a better fit regarding RMSE and ' $\mathrm{d}$ '. Therefore, depending upon the correlation as well as model performances, it is much more obvious from ANN model that the combination of DMI-SAM is much better predictors of rainfall than any other climate combinations. It seems that DMI and SAM is better and more reliable rainfall predictors than other indices affect South Australian rainfalls significantly. Moreover, SOI is also giving some significant agreements between input output relationships, where other phases of ENSO has no influences on spring rainfall.

Table 5. RMSE and ' $d$ ' values for the best models

\begin{tabular}{|c|c|c|c|c|c|}
\hline \multirow{2}{*}{\multicolumn{2}{|c|}{ Model }} & \multicolumn{4}{|l|}{ Model Performance } \\
\hline & & Training-Validation & Testing & Training-Validation & Testing \\
\hline \multirow{4}{*}{$\begin{array}{c}\text { Linear } \\
\text { Regression }\end{array}$} & & \multicolumn{2}{|l|}{ RMSE } & \multicolumn{2}{|l|}{$d$} \\
\hline & DMI-SOI & 24.08 & 19.57 & 0.58 & 0.60 \\
\hline & DMI-SAM & 24.46 & 15.30 & 0.58 & 0.68 \\
\hline & SOI-SAM & 24.76 & 21.96 & 0.52 & 0.40 \\
\hline \multirow{3}{*}{$\begin{array}{c}\text { Non-linear } \\
\text { ANN }\end{array}$} & DMI-SOI & 22.78 & 16.96 & 0.78 & 0.79 \\
\hline & DMI-SAM & 24.16 & 9.44 & 0.51 & 0.92 \\
\hline & SOI-SAM & 35.25 & 20.93 & 0.58 & 0.49 \\
\hline
\end{tabular}

ANN with combined-lagged climate predictors was able to model the observed rainfall in a way that the models follow the pattern of rainfalls several months in advance with very good accuracy. This shows that in order to forecast South Australian rainfall several months or seasons in advance, ANN modeling with the use of DMI-SAM as predictors can provide very reliable predictions, which can be used for water resources management and emergency resources planning.

\section{CONCLUSIONS}

This study is distinguished from previous studies by forecasting spring rainfall several seasons in advance by using the maximum possible lagged-time relationship of combined climate indices as a potential predictors (ENSO, IOD 
Rasel et al., Comparative study between linear and non-linear modelling techniques...

and SAM). Multiple regression was used as a linear and Artificial Neural Networks was used as a nonlinear technique in order to investigate the predictability of spring rainfall using lagged ENSO-DMI-SAM climate representatives. NINO3, NINO4, NINO3.4 and SOI were chosen as ENSO representatives and DMI was chosen as IOD representative. The previous studies were focusing on finding the effect of these climate indices separately on South Australian rainfalls but could not achieve a good correlation. This study discovered that lagged DMI-SAM has more effect on spring rainfall predictability than other combination of climate model and using DMI-SAM in an ANN model increased the model correlation up to $87 \%$ as opposed to the multiple regression models, with a correlation of $52 \%$.

This study concluded that non-linear artificial intelligence modelling technique is able to provide higher correlations and lower error to forecast rainfall compared to linear methods. There is a need to further investigate this method on other rainfall stations in this region to simplify the model which will be covered in future studies.

\section{REFERENCES}

Anwar, M. R., Rodriguez, D., Liu, D. L., Power, S., O’leary G. J. (2008). Quality and potential utility of ENSObased forecasts of spring rainfall and wheat yield in south-eastern Australia. Australian Journal of Agricultural Research 59: 112-126.

Cai, W., van Rensch, P., Cowan, T., Hendon, H. H. (2011). Teleconnection pathways of ENSO and the IOD and the mechanisms for impacts on Australian rainfall. Journal of Climate, 24(15), 3910-3923.

Chowdhury, R. K., Beecham, S. (2013). Influence of SOI, DMI and Niño3.4 on South Australian rainfall. Stoch. Env. Res. Risk A. 27(8): 1909-1920.

Cuddy, S., Letcher, R., Chiew, F. H. S., Nancarrow, B.E., Jakeman, T., (2005). A role for streamflow forecasting in managing risks associated with drought and other water crises, In Drought and Water Crises: Science, Technology and Management Issues, Wilhite DA (eds). CRC Press: Bocca Raton, FL, USA; 345-365.

Evans, A. D., Bennett, J. M. \& Ewenz, C. M. (2009). South Australian rainfall variability and climate extremes. Climate Dynamics, 33, 477-493.

Grimm, A. M. (2011). Interannual climate variability in South America: impacts on seasonal precipitation, extreme events, and possible effects of climate change. Stoch Environ Res Risk Assess 25(4): 537-554.

Kirono, D. G. C., Chiew, F. H. S., Kent, D. M. (2010). Identification of best predictors for forecasting seasonal rainfall and runoff in Australia. Hydrological Processes, 24(10), pp. 1237-1247.

Lin, F. J. (2008). Solving multicollinearity in the process of fitting regression model using the nested estimate procedure. Quality \& Quantity, 42(3), pp. 417-426.

Maier, H. R. and Dandy, G. C. (2000). Neural networks for the prediction and forecasting of water resources variables: a review of modelling issues and applications," Environmental Modelling and software, vol. 15, pp. 101-124.

Mekanik, F., Imteaz, M. A., Gato-Trinidad, S. and El-Mahdi, A. (2013) Multiple regression and Artificial Neural Network for long-term rainfall forecasting using large scale climate modes, Journal of Hydrology, Vol. 503, pp. 11-21.

Mekanik, F. and Imteaz, M. A. (2013). Capability of Artificial Neural Networks for predicting long-term seasonal rainfalls in east Australia, 20th International Congress on Modelling and Simulation MODSIM 2013, Adelaide, December.

Mekanik, F. and Imteaz, M. A. (2012). Forecasting Victorian spring rainfall using ENSO and IOD: A comparison of linear multiple regression and nonlinear ANN, 2nd International Conference on Uncertainty Reasoning and Knowledge Engineering, Jakarta, August.

Meneghini, B., Simmonds, I., Smith, I. N. (2007). Association between Australian rainfall and the Southern Annular Mode. International Journal of Climatology, 27(1), pp. 109-121.

Murphy, B. F. \& Timbal, B. (2008). A review of recent climate variability and climate change in southeastern Australia. International Journal of Climatology, 28, pp. 859-879.

Nicholls, N. (2010). Local and remote causes of the southern Australian autumn-winter rainfall decline, $1958-2007$. Climate Dynamics, 34(6), pp. 835-845.

Risbey, J. S., Pook, M. J., McIntosh, P. C., Wheeler, M. C., Hendon, H. H. (2009). On the remote drivers of rainfall variability in Australia. Monthly Weather Review, 137(10), pp. 3233-3253.

Schepen, A., Wang, Q. J., Robertson, D. (2012). Evidence for using lagged climate indices to forecast Australian seasonal rainfall. Journal of Climate, 25(4), pp. 1230-1246.

Shukla, R. P., Tripathi, K. C., Pandey, A. C., \& Das, I. M. L. (2011). Prediction of Indian summer monsoon rainfall using Niño indices: A neural network approach. Atmospheric Research, 102(1-2), pp. 99-109.

Ummenhofer, C. C., Sen Gupta, A., Pook, M. J., England, M. H. (2008). Anomalous rainfall over southwest Western Australia forced by Indian Ocean sea surface temperatures. Journal of Climate, 21, 5113-5134.

Verdon, D. C., Wyatt, A. M., Kiem, A. S., Franks, S. W. (2004). Multidecadal variability of rainfall and streamflow: Eastern Australia. Water Resources Research, 40, W10201.

Willmott, C. J. (1981). On the validation of models, Physical Geography, 2(2):184-194. 